\title{
A integralidade na visão dos fisioterapeutas de um município de médio porte *
}

Angela Carla Ghizoni ${ }^{1}$

Marina Patrício de Arruda²

Charles Dalcanale Tesser ${ }^{3}$

GHIZONI, A.C.; ARRUDA, M.P.; TESSER, C.D. Integrality: the perspective of physiotherapists from a medium-sized town. Interface - Comunic., Saude, Educ., v.14, n.35, p.825-37, out./dez. 2010.

This study aims to survey integrality from the perspective of physiotherapists in a medium-sized town. The research was carried out through self-administered questionnaires to professionals, and indepth interviews with six of them. For data treatment, we used content analysis, through which six different integrality faces emerged: the holistic face (viewing the patient as a whole), the enlarged face (emphasizing the social context and determinants of health-disease), the interdisciplinary face (interdisciplinary view contrasted to its absence in practice), the hidden face (lack of knowledge about the term; traces of integrality within daily practice), the fragmented face (mechanical view of the body), the null face (lack of knowledge; indifference). Such faces point to the need for adopting more integral practices by physiotherapists at private and public healthcare services. Therefore, professional education and permanent, continuing education are highlighted as two of the dimensions that characterize a socially constructed professional practice.

Keywords: Integrality. Physiotherapy. National Health System. Professional Education. Qualitative research.
Objetivou-se conhecer a visão dos fisioterapeutas acerca da integralidade em um município de médio porte. Foram utilizados questionários autoaplicados e entrevistas em profundidade com seis deles. Optou-se pela análise de conteúdo para tratamento dos dados. Emergiram seis diferentes faces da integralidade: holística (visão do paciente como um todo), ampliada (consideração do contexto e determinantes sociais da saúde-doença), interdisciplinar (visão interdisciplinar contrastada com a sua ausência prática), oculta (desconhecimento do termo; com indícios de prática da integralidade no cotidiano), fragmentária (visão mecânica do corpo) e face nula (desconhecimento e indiferença). Essas diversas e contraditórias faces indicam que a adoção de práticas mais integrais pelos fisioterapeutas deve ser fomentada nos serviços privados e públicos. Para tanto, ressalta-se a importância da formação profissional e da educação permanente e continuada como duas das várias dimensões que configuram o exercício profissional como uma prática socialmente construída.

Palavras-chave: Integralidade. Fisioterapia. Sistema Único de Saúde. Formação profissional. Pesquisa qualitativa.

\footnotetext{
* Elaborado com base em Ghizoni (2008), pesquisa que obedeceu aos preceitos da Resolução 196/96 do Conselho Nacional de Saúde e foi aprovada pelo Comitê de Ética em Pesquisa.

1 Universidade do Planalto Catarinense. Rua Hirto Luiz Melegari, 480. Sagrado Coração de Jesus, Lages, SC, Brasil. 88.508-395. angelcgfisio@yahoo.com.br 2 Programa de PósGraduação em Saúde Coletiva e Educação, Universidade do Planalto Catarinense. ${ }^{3}$ Departamento de Saúde Pública, Centro de Ciências da Saúde, Universidade Federal de Santa Catarina.
} 


\section{Introdução}

Este artigo apresenta e discute as faces da Integralidade em saúde que emergiram de um estudo realizado sobre a percepção de fisioterapeutas de um município catarinense de médio porte sobre a mesma. Em uma proposta de conhecer os sentidos e significados atribuídos pelos profissionais à integralidade, buscou-se esclarecer questões que dificultam o exercício pleno, efetivo e integrado do profissional de fisioterapia junto ao Sistema Único de Saúde (SUS).

A Constituição brasileira afirma que "a saúde é direito de todos e dever do Estado, garantido mediante políticas sociais e econômicas que visem à redução do risco de doença e de outros agravos e ao acesso universal e igualitário às ações e serviços para sua promoção, proteção e recuperação" (Brasil, 1988, art.196). Dessa forma, como menciona Mattos (2004, p.1412), a integralidade emerge como um dos princípios do SUS: "atendimento integral, com prioridade para as atividades preventivas, sem prejuízo dos serviços assistenciais". O SUS, como um "dispositivo institucional" criado para possibilitar o acesso universal e igualitário nos termos da Constituição, abarca todas as ações e serviços públicos de saúde e, ainda, alguns serviços privados por serem credenciados ao Sistema (Mattos, 2004, p.1412).

O fundamental na discussão deste princípio é que não se deve reduzir o sujeito à doença. Ao invés desta postura reducionista, é preciso manter a perspectiva da intersubjetividade (Mattos, 2004), levando em conta os conhecimentos sobre as doenças e sobre o humano que é, ao mesmo tempo, biopsicossocial. Isso implica a ampliação do olhar do profissional da saúde sobre o humano, pois, segundo Morin (2000), ser ao mesmo tempo biopsicossocial não significa que uma destas condicionantes/dimensões se sobreponha às restantes, nem que exista uma prioridade entre elas. Pelo contrário, significa que, sendo humano, qualquer uma de suas ações apresenta, simultaneamente, as dimensões biológica, psicológica, social e cultural - são interdependentes, indissociáveis. Portanto, o homem, como uma unidade complexa, deve ser atendido/cuidado como tal, sem ser dividido em partes - orientação esta fundamentada na reforma do pensamento e na compreensão do ser humano sob a perspectiva de um paradigma de complexidade.

No cotidiano da saúde pública, os profissionais se deparam com situações que exigem, além do conhecimento profissional, o conhecimento acerca do funcionamento do sistema de saúde vigente no país. Porém, a ausência deste conhecimento dificulta a efetivação de ações articuladas em saúde, problema que, muitas vezes, é enraizado nos currículos das instituições formadoras de fisioterapeutas.

Assim sendo, só depois de formado, o profissional passa a atender pelo SUS, sistema sobre o qual pouco sabe. Por ser estrutural, o problema se estende por várias gerações de formandos, perpetuando um trabalho inconsistente e desarticulado em razão da falta de conhecimento de muitos. Para que se possa auxiliar na efetivação de um sistema de saúde universal e igualitário, em que a integralidade seja mais que um slogan, faz-se necessário criar possibilidades de discussões e reflexões.

Mattos (2004), ao abordar a integralidade como um conceito polissêmico que se revela em diferentes saberes e práticas expressas no cotidiano da saúde, tece comentários sobre três dos sentidos que se aplicam ao termo. O primeiro refere-se a "respostas governamentais a certos problemas de saúde"; o segundo aplica-se à "organização dos serviços", e o terceiro diz respeito aos atributos das práticas de saúde" (Mattos, 2004, p.1411-2).

Sobre as práticas dos profissionais de saúde, Araújo, Miranda e Brasil (2007) destacam que uma série de aspectos vem sendo relacionada à ideia de integralidade. Dentre estes aspectos está o de que a visão integral do ser humano evita que o mesmo seja focalizado como um conjunto de partes (coração, fígado, pulmões etc.), inclui a valorização dos aspectos cotidianos da vida do paciente e evita práticas profissionais centradas apenas na doença. Estes aspectos, por sua vez, traduzem as percepções de alguns participantes desta pesquisa acerca de integralidade em saúde.

No caso desta pesquisa, os fisioterapeutas e suas compreensões foram o objeto e o foco de análise privilegiados. Apesar de se reconhecer a grande interinfluência da dimensão organizacional e da dimensão política - no caso, municipal - da abordagem do problema do provimento de cuidado fisioterápico à população que dele necessita, optou-se, por uma questão de recorte, conveniência e possibilidade metodológica - tempo e recursos escassos no contexto de um estudo de mestrado - por centrar a investigação nas percepções, compreensões e práticas dos profissionais. 
Como entende Mattos (2001), o termo integralidade possui diversas interpretações. Nesta pesquisa, foram identificadas as percepções dos fisioterapeutas como faces, que são compreendidas como aspectos, formas de ser, porque cada profissional tem a sua e conduz sua prática de maneira singular, seja ela mais ou menos integral. Sem a pretensão de esgotar a complexidade do tema, buscou-se problematizar práticas e percepções dando vistas às práticas singulares que se desenvolveram em diferentes clínicas de atendimento à saúde da população.

\section{Metodologia}

Realizou-se um estudo exploratório com abordagem qualitativa, tendo a integralidade e a percepção dos fisioterapeutas a respeito dela como eixos de discussão. Para tanto, a investigação destacou as subjetividades, as percepções, os conflitos, as contradições e, também, o potencial de transformação da prática profissional. Segundo Minayo (1994), a pesquisa qualitativa preocupa-se com um nível de realidade que não pode ser quantificado. Trabalha com um universo de significados, motivos, aspirações, crenças, valores e atitudes, o que corresponde a um processo profundo das relações humanas e sociais.

O município em que os sujeitos investigados atuavam, de acordo com dados do Instituto Brasileiro de Geografia (IBGE, 2006), apresenta área territorial equivalente a 2.644 km² e população estimada de 161.583 pessoas. Segundo pesquisa realizada pelo IBGE em 2005, a cidade contava com noventa estabelecimentos de saúde, 59 deles atendendo pelo SUS. Os habitantes da zona urbana encontram-se distribuídos em 65 bairros e, conforme dados da Secretaria do Estado da Saúde (www.saude.sc.gov.br), o município conta com 34 equipes de Saúde da Família com cobertura total a 70,9\% da população (www.lages.sc.gov.br).

O local é polo regional na área da saúde, possui laboratórios, clínicas especializadas e três hospitais. Conforme dados do Crefito10 (2007), há um total de 91 fisioterapeutas inscritos no Conselho Regional de Fisioterapia e Terapia Ocupacional, mas nem todos trabalham na cidade. Não havia, no momento da pesquisa, fisioterapeutas trabalhando em serviços públicos municipais. A população-alvo foi composta por todos os fisioterapeutas das clínicas locais, totalizando 32 participantes, seis deles credenciados ao SUS. Foram excluídos da pesquisa os fisioterapeutas que atuavam em clínicas de fisioterapia estética.

Procedeu-se à coleta de dados após a aprovação do projeto no Comitê de Ética em Pesquisa atendendo as exigências da Resolução 196/96 do Conselho Nacional de Saúde (Brasil, 1996).

Os instrumentos para a coleta de dados foram entrevistas em profundidade e um questionário com 14 questões abertas, que respaldam a construção deste artigo (além de sete perguntas fechadas aqui não utilizadas, relacionadas à graduação e ao perfil dos profissionais). Antes da coleta de dados, foram realizados três pré-testes do questionário e um pré-teste da entrevista com fisioterapeutas que não pertenciam à população-alvo da pesquisa. Isso auxiliou no aprimoramento dos instrumentos utilizados. O questionário, desenvolvido pela pesquisadora, era autoaplicado. As entrevistas em profundidade foram realizadas com seis fisioterapeutas, metade destes conveniados ao SUS.

As entrevistas foram realizadas com seis fisioterapeutas proprietários de clínicas credenciadas ao SUS, sendo selecionados por meio do critério de inclusão que considerou aqueles que tivessem mais tempo de atuação profissional, pois se entendeu que os relatos trariam maior riqueza de dados. As entrevistas foram gravadas e transcritas para análise.

Codificou-se o nome dos fisioterapeutas com intuito de se preservar a identidade dos mesmos. Os entrevistados que também responderam o questionário foram identificados como fisio1 a fisio6, e os profissionais que responderam somente o questionário foram identificados como fisio7 a fisio32.

Para tratamento dos dados, utilizou-se a análise de conteúdo, que, segundo Bardin (1979), é uma estratégia metodológica que permite a construção de um quadro de categorização prévio no qual foram dispostas dimensões teóricas assumidas e categorias delas derivadas para análise, assim como a exploração aberta do material em busca de temas (análise temática) que emergem do texto à luz dos objetivos e dos referenciais teóricos. As categorias de pesquisa analisadas no presente estudo foram: formação do fisioterapeuta e a integralidade em saúde. 


\title{
Resultados e discussão
}

Para compreender os sentidos e significados atribuídos ao princípio da integralidade, trataram-se os dados com base em diferentes concepções teóricas. Segundo Pinheiro e Mattos (2001, p.12), "integralidade é uma palavra que não pode ser nem ao menos chamada de conceito". Estes autores acrescentam que "na melhor das hipóteses é uma rubrica conveniente para o agrupamento de um conjunto de tendências cognitivas e políticas com alguma imbricação entre si, mas não completamente articuladas".

Alves $(2005$, p.43) destaca que o termo integralidade representa:

\begin{abstract}
Integrar ações preventivas, promocionais e assistenciais; integrar profissionais em equipes interdisciplinar e multiprofissional para uma compreensão mais abrangente dos problemas de saúde e intervenções mais efetivas; integrar partes de um organismo vivo, dilacerado e objetivizado pelo olhar reducionista da biomedicina, e reconhecer nele um sujeito, um semelhante a mim mesmo; nisto implica a assimilação do princípio da integralidade em prol da reorientação do modelo assistencial.
\end{abstract}

No trabalho de Alves (2005), a integralidade é analisada na Estratégia Saúde da Família (ESF), mas os sentidos acima mencionados podem ser atribuídos a todos os níveis da atenção. O importante é que sejam assimilados na atuação profissional, pelos profissionais envolvidos.

Mesmo se tratando de uma diretriz do Sistema de Saúde brasileiro, a integralidade também é vista como um ideal de atendimento, o que pressupõe ser um princípio de atendimento à saúde, e não uma exclusividade dos profissionais credenciados ou não ao SUS, como comenta a Fisio3, que considera praticar a integralidade:

“[...] eu acho que essa questão da integralidade, ela foi vinculada ao princípio do SUS, mas eu vejo que o processo é, da integralidade pra qualidade da saúde [...] esses princípios devem ser aplicados, como princípios de atendimento em saúde, independente de ser SUS, de ser convênio, de ser particular [...] porque a integralidade [...] é um modo de pensar, é um modo de agir, não é uma coisa que está vinculado àquele setor, àquela forma, ah se a sua forma é SUS então o senhor tem que ter eqüidade, integralidade, universalidade [...] ou você tem integralidade em todas as formas, ou você não tem". (fisio3)

Este depoimento mostra a integralidade como uma prática incorporada. A entrevistada menciona um "modo de agir e pensar", o que remete à prática fisioterapêutica, ou seja, uma teoria em ação (Gadotti, 1995).

Entendida como uma nova atitude em saúde, a integralidade é uma prática relatada a partir de experiências e expressa a possibilidade de se construírem caminhos para a efetivação de direitos. A integralidade como um modo de agir expressa, sobretudo, a força das transformações possíveis nos espaços cotidianos de trabalho, nos serviços e organizações sociais. A integralidade pode dar qualidade à saúde, que se desenvolve por meio de laços solidários do poder de novas redes e vínculos (Almeida, Feuerwerker, Llanos, 1999).

Machado et al. (2007), ao descreverem a integralidade no cuidado de pessoas, destacam a necessidade de se considerar o usuário como sujeito histórico e contextualizado na sociedade que se insere. "Neste cenário se evidencia a importância de articular as ações de educação em saúde como elemento produtor de um saber coletivo que traduz no indivíduo sua autonomia e emancipação para o cuidar de si, da família e do seu entorno" (Machado et al., 2007, p.336).

Concordando com a percepção de Mattos (2001), compreende-se que a integralidade tem uma dimensão plural que se revela em diferentes saberes e práticas no cotidiano do trabalho de educadores, profissionais de saúde, usuários e, até, de gestores. Em decorrência dessa multidimensionalidade ter se expressado neste estudo, e assim como fizeram Oliniski e Lacerda (2004) - que classificam o ambiente do trabalho em saúde por faces pela multidimensionalidade deste ambiente - também foram agrupados 
por faces os sentidos e significados da integralidade que emergiram das visões dos profissionais investigados.

Seguem, apresentadas e discutidas, as seis faces da integralidade em saúde surgidas da pesquisa. Faces que, embora algumas antagônicas entre si, podem conviver e sinalizam a existência de uma prática profissional plural e diversa - diversidade esta que necessita ser reconhecida, trabalhada e, por vezes, reconstruída.

\section{Face holística}

Esta face emergiu dos depoimentos dos fisioterapeutas com visão totalizadora do paciente, caracterizada pela indicação de "ver o todo". O relato da Fisio3, no questionário aplicado, evidencia esta visão mais globalizada do paciente:

"A forma como a pessoa pode ser tratada de forma completa e integral em um processo que o todo seja visto, por exemplo: condições de vida, rede social de apoio, vida familiar enfim avaliação e tratamento visando todos os aspectos do ser humano e como ele vive". (fisio3)

Ela acrescenta durante a entrevista:

"[...] tem que ver o todo do paciente [...] não adianta dizer, olha o senhor tem que fazer duas horas de bicicleta ergométrica por dia, tirando o fato de ele não ter condições nem de comprar o chinelo, se eu prescrever pra ele uma bicicleta ergométrica, vai ficar difícil. Eu acho que integralidade é ver tudo, é ver qual é a condição sócio-econômica do paciente, qual é a realidade $[\ldots] "$... (fisio3)

Cada contexto traz a possibilidade de se aprender e tem um poder de transformar ideias (Ribeiro, 2004). Desse modo, a prática não é apenas um espaço de verificação de ideias, mas também de construção de possibilidade e renovação teórica.

A visão holística de um paciente equivale a se ter uma "face única" e sintética de todas as partes. Com uma visão holística é mais seguro se tomarem decisões relativas à saúde do paciente. "Holismo" origina-se do grego Holos, que significa todo. A teoria da complexidade defende que o homem é um ser indivisível, que não pode ser entendido por meio de uma análise separada de suas diferentes partes.

A forma de agir, de tratar, de visualizar o paciente não somente como uma parte física lesionada, e sim de maneira global, ou seja, o físico, o mental, o sociocultural, é vista por esta profissional como sendo a integralidade. Ela também sinaliza a igualdade na forma de tratar os pacientes, sem dividi-los conforme a condição socioeconômica, como um modo de praticá-la. Os depoimentos dos entrevistados abaixo também revelam a mesma concepção:

"Atender o paciente de forma mais global e não só a patologia do mesmo trazendo à tona toda a condição social, cultural e econômica em que está inserido". (fisio11)

A fisioterapeuta a seguir menciona que é necessário visualizar o paciente de maneira holística, e alerta para o fato de que a doença pode ser originada pelo modo de vida que a pessoa adota:

Eu acho que é o que a gente faz, envolver a pessoa como um todo [...] tratar a pessoa como uma pessoa, não como aquele problema, não como aquele diagnóstico [...] eu não sou aquele diagnóstico, eu sou uma pessoa que tem uma vida de uma determinada maneira e que desenvolve determinada conseqüência por essa vida ser assim ou não; então a pessoa tem noção de qual é o correto do uso de si mesma". (fisio6) 
Esse relato traz à tona a importância do autoconhecimento como um fator auxiliador na melhoria da saúde dos pacientes. Dessa forma, coloca o humano como ser ativo e corresponsável por sua saúde, e o fisioterapeuta como auxiliador deste processo.

Aqui o olhar sistêmico é essencial para a compreensão do ser humano e da sua saúde, sendo impossível conhecer o todo sem conhecer as partes, e conhecer as partes sem conhecer o todo. $\mathrm{O}$ conceito sistêmico, segundo Morin (1987), exprime, simultaneamente, unidade, multiplicidade, totalidade, diversidade, organização e complexidade. A concepção situa-se imediatamente além do reducionismo, apelando para um princípio de inteligibilidade que integre as partes.

$\mathrm{Na}$ complexidade, a visão sistêmica é essencial para a compreensão do ser humano e da sua saúde. Morin (2003) defende a inter-poli-transdisciplinaridade como forma de integrar os saberes tão fragmentados e circunscritos aos limites das disciplinas, criadas pela necessidade imposta pelo modelo cartesiano. Assim, propõe a tão discutida mudança de paradigma, lançando o desafio da reforma do pensamento para se ter um pensamento complexo.

\section{Face ampliada}

Os fisioterapeutas que percebem esta face entendem a integralidade em saúde como a realização de ações conjuntas de promoção, prevenção e reabilitação. Uma visão ampliada de saúde pressupõe ações integradas e uma prática plena de possibilidades.

Na opinião de Mattos (2004, p.1414), defender a integralidade é:

Defender antes de tudo que as práticas em saúde sejam sempre intersubjetivas, nas quais profissionais de saúde se relacionem com sujeitos, e não com objetos - práticas intersubjetivas envolvem necessariamente uma dimensão dialógica. Isso confere às práticas de saúde um caráter de prática de conversação, na qual nós, profissionais de saúde, utilizamos nossos conhecimentos para identificar as necessidades de ações e serviços de saúde de cada sujeito com o qual nos relacionamos, para reconhecer amplamente os conjuntos de ações que podemos pôr em prática (incluindo ações como o aconselhamento e as chamadas práticas de educação em saúde) para responder as necessidades que apreendemos.

Além de a integralidade ser considerada como sinônimo de acesso a todos os níveis de complexidade do sistema, é relevante que haja, em todos esses níveis, articulações de ações preventivas e assistenciais. Ações assistenciais são demandadas a partir do sofrimento do indivíduo, já as preventivas antecedem a experiência individual de sofrimento. Nos dois tipos de ações é necessário que o profissional tenha conhecimento das doenças para interceder sobre elas ou evitá-las. A capacidade do profissional em responder ao sofrimento manifesto articulando ações preventivas e assistenciais é considerada por Mattos (2004) como uma das dimensões da palavra integralidade.

O Fisio1 comenta sua atitude diante de um paciente tabagista que chegou à clínica com problemas respiratórios:

“Eu o orientei que fazendo atividade física diária ia manter a pressão, perder peso, problema do coração e até mesmo o tabagismo, acho que o paciente que está fazendo fisioterapia respiratória, que fuma, eu sou sincero [...] o paciente tem que se ajudar primeiro, tem que abandonar o vício, não é só a gente ajudar o paciente. [...] oriento bastante eles: alimentação [...] cuidados como diminuir o sal, a gordura [...] é isso que a gente tenta fazer, orientações gerais durante o tratamento". (fisio1)

É relevante que, além de atender ao sofrimento manifestado pelo paciente e diagnosticado pelo médico, haja a apreensão dos chamados "fatores de risco" para o desenvolvimento de outras situações patológicas, e isso só se consegue com a visão ampliada e focada na saúde do paciente. Este entrevistado considera que a prática de atividade física tem muitos benefícios e a recomenda para os pacientes, assim como orientações alimentares, simbolizando a prática da educação em saúde. 
Embora as práticas educativas e preventivas possam ser mais ou menos dialogais ou diretivas (ou ainda autoritárias), é relevante salientar que a face ampliada aponta para uma atuação profissional que envolva também aspectos promocionais e preventivos, para além do caráter reabilitador da profissão, pelo que é mais comumente conhecida.

Para Alves (2005, p.42), o profissional deve estar preocupado em "dimensionar fatores de risco à saúde e, por conseguinte, na execução de ações preventivas, a exemplo da educação para a saúde". Para tratar o paciente por meio de uma visão ampliada de saúde, é preciso enxergá-lo não somente no aspecto biológico, mas implica acrescentar, ao tratamento fisioterapêutico, ações direcionadas à promoção da saúde e prevenção de doenças.

Além disso, dada a recente medicalização exacerbada dos fatores de risco e a redução dos umbrais terapêuticos a eles relacionados (como hipertensão e diabetes) (Norman, Tesser, 2009), assim como a tradição autoritária e a visão de educação em saúde como transmissão de informações a pessoas passivas que as devem seguir (Cyrino, Schraiber, 2009), outro desafio constante é fomentar a educação, promoção de saúde e prevenção de doenças sem recair em culpabilização dos usuários ou práticas autoritárias e medicalizantes pouco efetivas, que mais fazem amedrontar e espalhar insegurança, medo e dependência do que constroem parcerias e corresponsabilizações mútuas por processo de cuidado, de reinvenção e fortalecimento da vida.

A construção compartilhada entre profissionais e usuários de projetos terapêuticos sustentáveis, factíveis e integradores de cura, prevenção de doenças e promoção da saúde, não medicalizantes (Tesser, 2006a, 2006b), não culpabilizantes e não higiomaníacos (Nogueira, 2003a, 2003b, 2001), que fomentem a invenção da vida e a expansão das possibilidades da liberdade vivida com responsabilidade, é missão complexa da face ampliada da integralidade.

\section{Face interdisciplinar}

Esta face refere-se ao entendimento da integralidade enquanto trabalho em equipe interdisciplinar. É relevante que se possa inserir a interdisciplinaridade além do campo da educação para aplicá-la também ao campo da ação profissional na saúde. A interdisciplinaridade é considerada como ação de conhecimento, a postura interdisciplinar está no exercício do conversar, dialogar, trocar experiências e aprender. O profissional da saúde precisa ser condutor do processo de sua produção (Fazenda, 1996). É a partir da adoção de novos conceitos de saúde que haverá novos produtos em saúde. Alguns entrevistados percebem a integralidade como a união de profissionais da saúde sob uma perspectiva interdisciplinar:

"É atendimento integral, união dos profissionais com objetivo único". (fisio9)

"Integralidade é o comportamento do profissional de saúde em equipe e pela relação dessas equipes como uma rede de serviços, mas na prática é isso é difícil de acontecer, pela dificuldade de acesso com outros profissionais". (fisio15)

"Integralidade acontece quando uma pessoa integra a uma equipe, equipe multidisciplinar onde pessoas interagem e trocam informações. Fazem discussão de casos". (fisio28)

Observa-se que há clareza do conceito desta face entre os participantes, mas um deles sinaliza que a dificuldade de aplicá-la está no acesso aos demais profissionais deste nível da atenção, já que trabalham em locais distintos. Esta separação dificulta práticas realmente interdisciplinares.

No entendimento de Peduzzi (1998), a nenhum profissional de saúde cabe atender a totalidade de ações demandadas pelos usuários. A conexão entre os profissionais é fundamental para um atendimento focando a saúde integral do paciente. Reconhecer que o paciente necessita do olhar de outro profissional pode significar a interação para o início de um trabalho em equipe interdisciplinar. Entretanto, os participantes desta pesquisa mencionaram a dificuldade de contato com os médicos, profissionais que consideraram essenciais para a composição da equipe: 
"Eles são muito fechados [...] com o médico é difícil o acesso". (fisio1)

"Os médicos têm exceções. Tem aqueles que se consideram num cargo mais hierárquico, se sentem superiores então eles acham que tem poder, não atendem ligações, não respondem cartas". (fisio2)

"Para eu ligar hoje para um médico é muito difícil, porque as próprias secretárias já fazem barreira". (fisio4)

O modelo formador clássico flexneriano, tecnicista, biologicista, voltado para a prática hospitalar e médico-centrado, é um tipo de formação que não contempla todas as necessidades básicas de saúde da população. Hoje, porém, se questiona o sistema de saúde centrado no médico e todo um processo/ organização que durante muito tempo garantiu a essa categoria profissional o distanciamento hierárquico de outras profissões.

Formar profissionais de saúde sob a perspectiva da integralidade constitui uma proposta inovadora, e significa a ruptura não só com um modelo tradicional de formação, mas também implica a reorganização dos serviços e a análise crítica dos processos de trabalho.

Japiassu (1976) destaca que cada disciplina, por meio de seu enfoque específico, desenvolve instrumentos para se conhecerem a realidade e os problemas com base em um determinado ponto de vista, mas essa visão unidisciplinar necessariamente fragmenta, reduz e privilegia a decomposição do todo em partes. Com o desenvolvimento do conhecimento humano, a perspectiva de interconexão amplia a visão, permitindo a compreensão da complementaridade entre os sabres e as profissões.

\section{Face oculta (escondida)}

Essa face mostra o desconhecimento do profissional acerca dos significados da integralidade, mas indica certa presença da mesma, por meio de posturas e procederes que o colocam como educador e investigador dos aspectos biopsicossociais do paciente, com olhar atento às necessidades para a melhoria da saúde. Como o Fisio2, que verbaliza: "não sei, não lembro, me foge um pouco; até é uma coisa que eu não gosto de saber"; porém, logo em seguida (sobre como realiza a avaliação fisioterapêutica), diz:

“[...] o psicológico, físico e mental e o social [...] só que não é em uma avaliação [...] é na conversa diária com ele que você vai pegando os pontos positivos e negativos do paciente, vai acrescentando o seu tratamento e na própria indicação ou nos cuidados na prevenção, passando orientações [...] eu gosto de ser amigo dos meus pacientes [...] eu trato todos igual: SUS ou particular [...] a confiança é o que faz o paciente seguir as orientações que você passa". (fisio2)

Mesmo sem explicitarem conscientemente o significado do termo, vários profissionais conseguem praticar algo das faces holística e ampliada. Também Mattos (2004, p.1415) comenta que "há muitos profissionais que, mesmo sem uma formulação teórica da proposta, ou mesmo sem utilizar o termo, praticam a integralidade no seu cotidiano". Propiciar diálogo, visibilidade, valorização e ressignificação das boas práticas já existentes certamente é valioso e, muitas vezes, necessário, possibilitando a conexão de tais práticas com a missão da integralidade, de forma a expandir sua potencialidades. Isso é um desafio para os gestores de serviços de SUS e para os formadores de profissionais.

Tanto em serviços públicos como conveniados, muitos profissionais se beneficiariam de arranjos institucionais que permitissem alguma educação permanente ${ }^{4}$ e discussão de suas práticas, de modo a ampliar suas possibilidades no sentido do reconhecimento de alguma integralidade já existente e praticada e de sua ampliação na abordagem dos usuários e seus problemas.

O que importa é que, com base nessa visão mais abrangente adotada, buscar soluções para as novas demandas, antes negligenciadas, pode explicitar a necessidade de mudança para a saúde. 
${ }^{4}$ No sentido dado ao termo por Peduzzi (2009):

a educação permanente é fundamentada na concepção de educação como transformação e aprendizagem significativa, centrada no exercício cotidiano do processo de trabalho, na valorização do trabalho como fonte de conhecimento, na valorização da articulação com a atenção à saúde, a gestão e o controle social, e no reconhecimento de que as práticas são definidas por múltiplos fatores. Neste contexto, a educação dos profissionais ainda volta-se à multiprofissionalidade e à interdisciplinaridade, com estratégias de ensino contextualizadas e participativas, e orienta-se para a transformação das práticas. Tais características diferenciam-na da

educação continuada, pautada na concepção de educação como transmissão

de conhecimento e na valorização da ciência como fonte do

conhecimento, pontual, fragmentada e construída de forma não articulada à

gestão e ao controle social, com enfoque nas categorias profissionais $\mathrm{e}$ no conhecimento técnicocientífico de cada área.

${ }^{5}$ Abraham Flexner comandou uma pesquisa sobre o ensino médico nas escolas de medicina dos Estados Unidos e Canadá, e produziu, em 1910, famoso Relatório Flexner, aceito pelo governo americano, que a partir dele fechou muitas escolas médicas e reformulou os critérios para o

funcionamento das escolas, instituindo o modelo dito flexneriano de ensino médico, centrado nos laboratórios, no ambiente hospitalar e suas patologias graves e raras, nas especialidades médicas e no uso intensivo de tecnologia diagnóstica e terapêutica "duras". De 1910 a 1930, inicia-se a era da especialização na medicina. Ver o Relatório

Flexner em: <http:// www.carnegiefoundation. org/files/elibrary/ flexner report.pdf $>$

\section{Face fragmentada (anti-integralidade)}

Esta face é percebida pelos entrevistados que expressam, na prática, a fragmentação do saber, a constante busca pela especialização e a visão reducionista do indivíduo. O pensamento cartesiano sempre volta e mostra que, na área da saúde em geral, e da fisioterapia em particular, alguns profissionais ainda tendem a enfatizar a despersonalização da pessoa enferma quando, por exemplo, se referem a ela como uma máquina ou um amontoado de peças:
“Então, eu enxergo o meu paciente como uma máquina cheia de peças que se articulam umas sobre as outras [...] eu investigo muito disfunções articulares que possam gerar alterações, ou dores em relação aos processos de degeneração, aos processos de inflamatórios [...] é mais a área de Ortopedia e Traumatologia [...] pra que o corpo funcione de uma maneira correta ele precisa ter os movimentos nos seus eixos adequados". (fisio5)

A visão dos pacientes como "máquina" e a dissociação do humano em partes, para tratá-lo, remete, como já mencionado, ao modelo de ensino e prática biologicista, fragmentador, unicausal e positivista que, em 1910, com a publicação do Relatório Flexner ${ }^{5}$, teve grande impulso no ensino médico norteamericano, vindo posteriormente a influenciar o ensino das demais profissões da saúde, de modo ainda hoje presente no processo de formação dos profissionais da saúde.

Esta orientação instigava o reducionismo, a fragmentação do corpo. Tal modelo é objeto de crítica para profissionais que já atuam sob a perspectiva da integralidade em saúde. Neste sentido, parece importante repensar o processo de formação profissional da saúde com características que tornem os acadêmicos capazes de construírem conhecimentos que superem as dicotomizações, tendo presente que as pessoas são corporeidades complexas e vivem em contextos complexos (Vieira, Baggio, Maraschim, 2007).

Mattos (2001, p.62) ilumina o relato mencionando que "há profissionais que, impossibilitados de tratar com sujeitos, tratam apenas das doenças", e não os veem como portadores de "desejos, de aspirações, de sonhos". Ele define esse modo de agir como incapacidade de criar uma relação com o outro, a não ser transformando-o em objeto, ou no caso do relato desse fisioterapeuta, transformando o paciente em uma máquina, desmembrando-o para tratar a "peça" debilitada.

Morin (2000) amplia esta compreensão destacando que o ser humano é, a um só tempo, físico, biológico, psíquico, cultural, social e histórico. Esta unidade complexa da natureza humana é totalmente desintegrada na educação por meio das disciplinas, tornando impossível aprender o que significa ser humano. É preciso restaurá-la, de modo que cada um, onde quer que se encontre, tome conhecimento e consciência, ao mesmo tempo, de sua identidade complexa e de sua identidade comum a todos os outros humanos.

\section{Face nula}

Nesta face não há conhecimento nem prática da integralidade, com a confusão sobre o termo presente em alguns depoimentos: 
“Eu até não sei se eu não deixei em branco essa pergunta (no questionário). Eu não entendo [...] se essa integralidade é o espaço físico, racional e emocional, eu não sei". (fisio4)

$\mathrm{Na}$ análise da entrevista desse profissional, observa-se que não há indícios da prática da integralidade no seu atendimento ao paciente, caracterizando um profissional alheio ao conhecimento do SUS e à prática de um de seus princípios, apesar de ser prestador de serviços ao sistema.

Esse desconhecimento é importante e contribui para que esse profissional não consiga praticar e nem perceber algum dos significados que compõem a multiplicidade semântica abarcada pela integralidade. Essa ausência de aspectos da integralidade na abordagem profissional, juntamente com a anti-integralidade (face fragmentada) mencionada antes, podem estar presentes em muitos serviços públicos e privados do país e nas escolas formadoras de profissionais, o que certamente faz degradar em algum grau a qualidade do cuidado fisioterapêutico. A dimensão da extensão de sua presença é uma incógnita, e serão necessárias outras pesquisas em outros contextos para dimensioná-la.

Em todo caso, sua presença implica mais um desafio para os gestores do SUS, na medida em que significa a necessidade de seu reconhecimento como um tipo de prática presente e uma dificuldade adicional para o provimento de cuidados aos cidadãos brasileiros: além de viabilizar acesso ao cuidado fisioterapêutico para os que dele necessitam, tarefa já bem difícil, há que se reconhecer e valorizar nele a presença da face oculta ou escondida da integralidade e fomentar a construção e a expansão das características das faces holística, ampliada e interdisciplinar da mesma, ao mesmo tempo em que se necessita transformar as faces fragmentadas e nulas.

\section{Considerações finais}

Parece ser imperativo reconhecer na fisioterapia, assim como provavelmente nas demais práticas profissionais em saúde, que os sentidos da integralidade variam muito e associam-se a práticas que podem ser consideradas integrais, menos ou não integrais. Pela polissemia do termo integralidade, identificaram-se os sentidos e significados atribuídos à integralidade, pelos fisioterapeutas, como faces que variaram de acordo com o entendimento de quem as descreveu. Notou-se que a face holística foi a mais usada pelos participantes da pesquisa para conceituar o termo, citada como aquela capaz de entender o humano como ser biopsicossocial, e não reduzi-lo à parte física debilitada.

A face fragmentada ou anti-integralidade chamou a atenção para uma prática ainda existente. Nessa face constatou-se a influência de uma formação "de base flexneriana", biologicista, que estimula um conhecimento fragmentado pela constante especialização. Para a reversão deste quadro, os fisioterapeutas precisam ser capacitados para desempenharem atividades considerando o indivíduo na sua multiplicidade, globalidade e contexto existencial, atuando com um olhar ampliado para a saúdedoença e seus condicionantes.

É importante salientar que as faces apresentadas não esgotam toda a multiplicidade do termo integralidade, tratando apenas dos sentidos que emergiram das falas dos profissionais entrevistados.

A visão da integralidade, para alguns, é de uma utopia (Mattos, 2004), para outros, de compromisso e, ainda, de confusão e desconhecimento. A pesquisa mostrou que, na prática dos fisioterapeutas, a integralidade se traduz em faces variadas. Esta multidimensionalidade existe em decorrência, provavelmente, de uma formação profissional heterogênea, associada a contextos institucionais diversos e por vezes anti-integrais de cuidado.

Este estudo partiu do pressuposto de que a adoção de novos paradigmas no campo da saúde coletiva, no âmbito das práticas, enfrenta distintos desafios, dentre eles a percepção e compreensão que os profissionais - no caso, fisioterapeutas - têm do termo integralidade em saúde. Ele possibilitou trazer à tona aspectos relevantes sobre a diversidade de percepções que os fisioterapeutas possuem a respeito do tema. As faces que emergiram dos depoimentos colhidos mostram a diversidade de práticas e entendimentos, sinalizando a complexidade do campo da saúde e a responsabilidade na formação e na educação permanente dos fisioterapeutas. 
O provimento de um somatório de serviços disciplinares ou profissionais especializados (como de fisioterapia) isolados uns dos outros parece não ser suficiente para um cuidado longitudinal efetivo e integral. É imprescindível que escolas de graduação e seus docentes realizem um processo de ensino e capacitação adequado para formar profissionais com base nas diretrizes curriculares, capazes de atuarem em concordância com os princípios do sistema de saúde público vigente no país.

Por outro lado, os resultados permitem sugerir que os gestores locais do SUS também precisam atuar de forma a reconhecerem e reconstruírem os significados e as práticas profissionais, associando-os à missão da integralidade, viabilizando e induzindo processos de educação permanente entre seus trabalhadores, bem como fomentando: arranjos institucionais, matriciamentos, formas de gestão democráticas e responsáveis, construção de parcerias e apoios personalizados, de modo a enriquecerem as possibilidades de trabalho interdisciplinar, necessário para um maior teor de integralidade nas práticas de cuidado e na organização do Sistema.

Os processos de formação e capacitação profissional e educação permanente, bem como o trabalho interdisciplinar, precisam ser realmente constantes e conectados com as necessidades do SUS e sua proposta de integralidade, para se tornarem efetivos.

\section{Colaboradores}

Angela Carla Ghizoni responsabilizou-se pela coleta e organização dos dados e, juntamente com Marina Patrício de Arruda, por todas as etapas da elaboração e revisão da pesquisa e do artigo. Charles Dalcanale Tesser responsabilizou-se pela revisão geral da pesquisa, da discussão dos dados, da concepção e das fases de redação do artigo.

\section{Referências}

ALMEIDA, M.; FEUERWERKER, L.; LLANOS, M. (Orgs.). A educação dos profissionais de saúde na América Latina: teoria e prática de um movimento de mudança. São Paulo: Hucitec, 1999.

ALVES, V.S. Um modelo de educação em saúde para o Programa Saúde da Família: pela integralidade da atenção e reorientação do modelo assistencial. Interface - Comunic, Saude, Educ., v.9, n.16, p.39-52, 2005. Disponível em: <http://www.scielo.br/pdf/ icse/v9n16/v9n16a04.pdf>. Acesso em: 20 jan. 2009.

ARAÚJO, D.; MIRANDA, M.C.G.; BRASIL, S.L. Formação de profissionais de saúde na perspectiva da integralidade. Rev. Baiana Saude Publica, v.31, supl.1, p.20-31, 2007.

BARDIN, L. Análise de conteúdo. Lisboa: Edições 70, 1979.

BRASIL. Constituição da República Federativa do Brasil. Brasília: Senado, 1988.

Disponível em: <https://www.planalto.gov.br/ccivil_03/

Constituiçao_Compilado.htm >. Acesso em: 27 out. 2007.

Conselho Nacional de Saúde. Resolução n¹96 de 10 de outubro de 1996.

Diretrizes e normas regulamentadoras de pesquisas envolvendo seres humanos. Brasília: Ministério da Saúde, 1996.

CONSELHO REGIONAL DE FISIOTERAPIA E TERAPIA OCUPACIONAL DA $10^{\text {a }}$ REGIÃO - CREFITO10. Disponível em: <http://www.crefito10.com.br>. Acesso em: 7 set. 2007. 
CYRINO, A.P.; SCHRAIBER, L.B. Promoção da saúde e prevenção de doenças: o papel da educação e da comunicação. In: MARTINS, M.A. et al. (Orgs.). Clínica médica: atuação da clínica médica, sinais e sintomas de natureza sistêmica, medicina preventiva, saúde da mulher, envelhecimento e geriatria, medicina laboratorial na prática médica. 1.ed. Barueri: Manole, 2009. v.1. p.470-7.

FAZENDA, I.C.A. Integração e interdisciplinaridade no ensino brasileiro: efetividade ou ideologia? 4.ed. São Paulo: Loyola, 1996.

GADOTTI, M. Pedagogia da práxis. São Paulo: Cortez, 1995.

GHIZONI, A.C. As faces da integralidade em saúde: estudo sobre a percepção dos fisioterapeutas das clínicas de Lages (SC). 2008. Dissertação (Mestrado) - Programa de Pós-Graduação em Saúde Coletiva, Universidade do Planalto Catarinense, Lages. 2008.

INSTITUTO BRASILEIRO DE GEOGRAFIA E ESTATÍSTICA. IBGE cidades@, 2006. Disponível em: <http://www.ibge.gov.br/cidadesat/topwindow.htm?1>. Acesso em: 29 jun. 2007.

JAPIASSU, H. Interdisciplinaridade e patologia do saber. Rio de Janeiro: Imago, 1976.

MACHADO, M.F.A.S. et al. Integralidade, formação de saúde, educação em saúde e as propostas do SUS - uma revisão conceitual. Cienc. Saude Colet., v.12, n.2, p.335-42, 2007.

MATTOS, R.A. A integralidade na prática (ou sobre a prática da integralidade). Cad. Saude Publica, v.20, n.5, p.1411-6, 2004.

Os sentidos da integralidade: algumas reflexões acerca de valores que merecem ser defendidos. In: PINHEIRO, R.; MATTOS, R.A. (Orgs.). Os sentidos da integralidade na atenção e no cuidado à saúde. Rio de Janeiro: IMS/UERJ/Abrasco, 2001. p.39-64.

MINAYO, M.C.S. Pesquisa social: teoria, método e criatividade. Petrópolis: Vozes, 1994.

MORIN, E. A cabeça bem feita: repensar a reforma, reformar o pensamento. Rio de Janeiro: Bertrand Brasil, 2000.

O método: o conhecimento do conhecimento. Lisboa: Publicações EuropaAmérica, 1987. 2003.

Os sete saberes necessários à educação do futuro. 2.ed. São Paulo: Cortez,

NOGUEIRA, R.P. A saúde pelo avesso. Natal: Seminare Editora, 2003a.

A segunda crítica social da Saúde de Ivan Illich. Interface - Comunic., Saude, Educ., 2003, v.7, n.12, p.185-90, 2003b.

Higiomania: a obsessão com a saúde na sociedade contemporânea. In: VASCONCELOS, E.V. (Org.). A saúde nas palavras e nos gestos: reflexões da rede educação popular e saúde. São Paulo: Hucitec, 2001. p.63-72.

NORMAN, A.H.; TESSER, C.D. Prevenção quaternária na atenção primária à saúde: uma necessidade do Sistema Único de Saúde. Cad. Saude Publica, v.25, n.9, p.2012-20, 2009.

OLINISKI, S.R.; LACERDA, M.R. As diferentes faces do ambiente de trabalho em saúde. Cogitare Enferm., v.9, n.2, p.43-52, 2004. Disponível em: <http://ojs.c3sl.ufpr.br/ ojs2/index.php/cogitare/article/viewFile/1715/1423>. Acesso em: 23 mar. 2009.

PEDUZZI, M. Atividades educativas de trabalhadores na atenção primária: concepções de educação permanente e de educação continuada em saúde presentes no cotidiano de Unidades Básicas de Saúde em São Paulo. Interface - Comunic., Saude, Educ., v.13, n.30, p.121-34, 2009. 
PEDUZZI, M. Equipe multiprofissional de saúde: a interface entre trabalho e interação. 1998. Tese (Doutorado) - Universidade Estadual de Campinas, Campinas. 1998.

PINHEIRO, R.; MATTOS, R.A. Os sentidos da integralidade na atenção e no cuidado à saúde. 3.ed. Rio de Janeiro: UERJ/Abrasco, 2001.

RIBEIRO, E. Educação permanente em saúde. In: MARINS, J.J.N. et al. (Orgs.). Educação médica em transformação: instrumentos para a construção de novas realidades. São Paulo: Hucitec, 2004. p.285-303.

TESSER, C.D. Medicalização social (I): o excessivo sucesso do epistemicídio moderno na saúde. Interface - Comunic, Saude, Educ., v.10, n.19, p.61-76, 2006.

Medicalização social (II): limites biomédicos e propostas para a clínica na atenção básica. Interface - Comunic., Saude, Educ., v.10, n.20, p.347-62, 2006.

VIEIRA, P.S.; BAGGIO, A.; MARASCHIM, R. Competências desenvolvidas por acadêmicos de fisioterapia e implicações para o exercício profissional. Rev. Dig., v.12, n.112, 2007. Disponível em: <http://www.efdeportes.com/>. Acesso em: 13 dez. 2008.

GHIZONI, A.C.; ARRUDA, M.P.; TESSER, C.D. La integralidad en la visión de los fisioterapeutas de un municipio de porte mediano. Interface - Comunic., Saude, Educ., v.14, n.35, p.825-37, out./dez. 2010.

Se ha objetivado conocer la visión de los fisioterapeutas sobre la integralidad en un municipio de porte mediano. Se utilizan cuestionarios auto-aplicados a los fisioterapeutas en profundidad con seis de ellos. Se ha optado por el análisis de contenido para el tratamiento de datos. Emergen seis diferentes aspectos de la integralidad: holístico (visión del paciente como un todo), ampliado (consideración del contexto y determinantes sociales de la salud-enfermedad), interdisciplinario (visión interdisciplinaria contrastada con su ausencia práctica), aspecto oculto (desconocimiento del término con indicios de práctica de la integralidad en lo cotidiano), fragmentario (visión mecánica del cuerpo) y aspecto nulo (desconocimiento e indiferencia). Los diferentes y contradictorios aspectos de la integralidad recomiendan la adopción de prácticas más integrales. Para tal, se resalta la importancia de la formación profesional y de la educación permanente y continuada como dos de las varias dimensiones que configuran el ejercicio profesional como una práctica socialmente construida.

Palabras clave: Integralidad. Fisioterapia. Sistema Único de Salud. Formación profesional. Investigación cualitativa. 